\title{
ORÍGENES Y DESARROLLO DEL TURISMO EN EL PROTECTORADO ESPAÑOL DEL NORTE DE MARRUECOS (1912-1956) ${ }^{1}$
}

\author{
Eduardo Araque Jiménez
}

Universidad de Jaén

\section{RESUMEN}

A lo largo del casi medio siglo durante el cual España ejerció el Protectorado en el norte de Marruecos (1912-1956), tanto la iniciativa pública como la privada trataron de impulsar la implantación y el desarrollo del turismo en ese país con una doble finalidad. Por un lado, crear una nueva fuente de riqueza y empleo que contribuyera a la mejora material de una sociedad con profundos síntomas de subdesarrollo; por otro lado, exhibir ante los visitantes los logros alcanzados por la denominada «acción civilizadora» española.

Palabras clave: Turismo; Protectorado; Marruecos; Comité de turismo; Servicio de turismo.

\section{Beginnings and development of tourism in the Spanish Protectorate in Northern Morocco (1912-1956)}

\section{ABSTRACT}

During half a century that Spain exert the Protectorate in the north of Morocco (19121956), the public and private initiative tried to promote the establishment and development of tourism in this region with a double objective. On the one hand, to create a new source of riches and employment that contributed to the improvement of a society with deep signs of underdevelopment; in the other hand, to show to visitors the achievement reached by the called Spanish «civilizing action».

Keywords: Tourism; Protectorate; Morocco; Tourism Committee; Tourism Service.

Recibido: 25 de enero de 2014

Devuelto para su revisión: 5 de septiembre de 2014

Aceptado: 10 de octubre de 2014

Área de Análisis Geográfico Regional. Universidad de Jaén. Paraje las Lagunillas. 23071 JAÉN (España). E-mail: earaque@ujaen.es

1 Este trabajo se ha realizado en el marco del «Proyecto Alborán. Desarrollo territorial en el norte de Marruecos», financiado por la Agencia Española de Cooperación Internacional para el Desarrollo (A1/036023/11). 


\section{INTRODUCCIÓN}

Desde comienzos del siglo actual el turismo se ha convertido en uno de los pilares fundamentales de la estrategia de relanzamiento de la economía marroquí. Los distintos planes sectoriales que se han aprobado desde entonces, han prestado una atención especial a las costas septentrionales del país, sin duda por sus grandes atractivos y enormes posibilidades de cara a la implantación y desarrollo de esta actividad, pero también por su cercanía a los dos focos de emisión de turistas hacia Marruecos más activos en los últimos años, situados en Francia y España, por este mismo orden de importancia² .

En buena parte de esta franja costera bañada por el océano Atlántico y el mar Mediterráneo, el turismo goza de una dilatada tradición que se remonta a los años en que España comenzó a ejercer el Protectorado sobre la misma (1912-1956). Aunque, como es sobradamente conocido, durante las primeras décadas de ese período histórico toda esta zona fue escenario de frecuentes escaramuzas y conflictos bélicos de envergadura, muy poco propicios para el desarrollo de una actividad como la turística, lo cierto es que las autoridades civiles españolas, desde el momento en que asumieron los compromisos contenidos en el convenio franco-español suscrito en 1912, pusieron todo su empeño en lograr que la porción de territorio que le había correspondido administrar a España fuera conocida más allá de sus estrechas fronteras y suscitara un atractivo capaz de motivar la visita turística de esta porción del territorio marroquí. Y no ya sólo estaban interesadas en los beneficios económicos y sociales que podía deparar tal actividad a la sociedad receptora, sino también porque consideraban al turismo como un modo de publicitar la labor de España en esta parte del territorio africano, donde la presencia de nuestro país no siempre fue bien entendida ni aceptada ni por una parte de la sociedad marroquí ni de la española. Por ambas razones, desde la Alta Comisaría, en cuanto existió disponibilidad de medios, se desplegó una intensa actividad propagandística y se apoyaron otras muchas iniciativas encaminadas al establecimiento del turismo en las diferentes regiones en que quedó dividido el Protectorado español.

En este trabajo nos proponemos rastrear los orígenes de esta nueva actividad en la zona que le tocó administrar a España durante casi medio siglo, exponiendo y explicando los hitos más significativos que marcaron el proceso de afianzamiento y consolidación turística; un proceso que no podemos disociar, en primer lugar, de las mejoras experimentadas en la red de comunicaciones interiores y en las conexiones con el exterior a través de España, imprescindibles para comprender el incremento del tránsito de viajeros. Tampoco pueden entenderse sin explicar el paulatino incremento de la capacidad de acogida turística, cuya conformación no se debió únicamente al esfuerzo de la iniciativa privada, sino que correspondió también a la colaboración de la iniciativa pública. Por último no podemos menospreciar el relevante papel que desempeñó la acción institucional en estos momentos iniciales de despegue del turismo; la política turística que en cada momento se siguió desde la Alta Comisaría como un fiel reflejo de lo que coetáneamente estaba sucediendo en España. Con la explicación somera de todo ello tratamos de contribuir

2 Véase «Tourisme 2030. Quelles ambitions pour le Maroc?». En línea http://www.hcp.ma/downloads/ Maroc-2030_t11885.html. Revisado 12 de noviembre de 2014. 
al conocimiento de una de las fuentes de creación de riqueza y empleo a las que hasta ahora apenas se ha prestado atención en la profusa bibliografía que se ha consagrado al Protectorado, seguramente porque no arrojó resultados tan espectaculares o, al menos, éstos no fueron tan suculentos, como los que se obtuvieron en otros ámbitos económicos privilegiados por la actuación española.

\section{RÍO MARTÍN, LA PLAYA DE TETUÁN}

Desde el momento en que se instauró el Protectorado, Tetuán se convirtió en su capital administrativa, así como en uno de los principales centros de estacionamiento de las tropas españolas destacadas en Marruecos. Funcionarios civiles llegados de toda España comenzaron a ocupar las numerosas plazas que se les ofrecían en los distintos destinos de la nueva Administración protectoral, cuyo atractivo más estimulante provenía de los generosos complementos económicos que, junto con el sueldo, percibían mensualmente los empleados públicos; un montante que podía llegar a duplicar perfectamente el que por las mismas funciones percibían en la Península. A esa fracción de población civil, muy pronto se le unieron los familiares de los miles de soldados profesionales destinados en los diferentes cuarteles y destacamentos localizados en Tetuán o en sus inmediaciones; una colonia que fue creciendo de forma paulatina a medida que las circunstancias bélicas de cada momento lo requirieron. Todo este contingente de población española encontró un magnífico lugar de asueto y esparcimiento junto al Mediterráneo en la pequeña localidad costera de Rio Martín, distante apenas siete kilómetros de la ciudad de Tetuán. Sus playas, situadas a ambos lados del pequeño puerto enclavado en la desembocadura del río Martín, se convirtieron en el más concurrido lugar de encuentro de los españoles en los tórridos meses veraniegos. A ello contribuyó de manera decisiva el establecimiento de una pequeña línea férrea que unía ambas localidades, inaugurada a finales de 1913. Destinada en sus orígenes al traslado de víveres y mercancías militares, poco después quedó abierta también al tráfico de pasajeros. Eso facilitó considerablemente el desplazamiento diario hasta las playas mediterráneas.

En los primeros años del Protectorado, la frecuentación del litoral próximo a Río Martín por la colonia española residente en Tetuán, resultó esporádica, debido a la escasa dotación de servicios para atención de los bañistas y, desde luego, al mal estado general de las playas, abatidas de continuo por temporales que acababan engullendo las arenas y ocasionando toda clase de desperfectos en el escaso mobiliario urbano. A pesar de este inconveniente, y para remediar la carencia de servicio, en 1914 ya se registraba la petición al Jalifa por parte de un particular para abrir un balneario-restaurante en la playa de Río Martín, la cual era concedida de inmediato por las ventajas para la higiene y salubridad públicas que reportaba este establecimiento. La única condición que se imponía al solicitante era que los agentes de aduana pudieran inspeccionar el local cada vez que lo consideraran conveniente, sin duda para evitar que esas instalaciones próximas a la zona portuaria pudieran utilizarse por los abundantes contrabandistas para sus operaciones.

La fijación de las extensas zonas dunares aledañas a la desembocadura del río, en un primer momento, y la planificación del crecimiento urbano, poco después, mejoraron ostensiblemente las condiciones de estancia y utilización playera de Río Martín. Gracias 
a ello, poco a poco empezaron a abrirse pequeños bares, restaurantes y viviendas de alquiler que posibilitaron la presencia de un cierto contingente estable de veraneantes en la ciudad. A ellos había que añadir otros colectivos que utilizaban la playa mediante el emplazamiento de tiendas de campaña y otra clase de alojamientos precarios, cuyo número crecía de temporada en temporada, tal y como se recordaba en 1918 el propio Boletín Oficial de la Zona de Influencia Española en Marruecos: «el campamento que en la playa cercana a la desembocadura de río Martín acostumbran a poner los tetuaníes y que ya el año último estuvo muy concurrido, ha estado este año aun más animado, y puede decirse que la totalidad de las personas acomodadas de Tetuán y muchas de las clases pobres han acudido a la playa de Río Martín con sus mujeres e hijos demostrando su confianza en la seguridad existente».

A partir de los años veinte, como ya hemos señalado en otro lugar (Araque Jiménez y Garrido Almonacid, 2008), el crecimiento urbano de este núcleo resultó espectacular. A comienzos de esa década ya tenemos constancia de la existencia de distintos chalets de lujo pertenecientes a individuos pudientes de Tetuán, en alguno de los cuales solía veranear el Jalifa. Lo habitual, sin embargo, era que la máxima autoridad marroquí del Protectorado instalara su tienda de campaña y las de su abundante séquito en las mismas playas de Río Martín, donde era frecuente que acudieran a visitarlo los representantes políticos y militares españoles, bien para despachar asuntos de gobierno, bien para participar en las numerosas fiestas que el Jalifa organizaba durante su periodo vacacional.

La ampliación del núcleo urbano proyectada por Carlos Ovilo en 1927, puso a disposición de los promotores inmobiliarios una enorme porción de suelo urbano paralela a la costa, destinada al nuevo uso residencial. Ello posibilitó la llegada de nuevos residentes pertenecientes, por lo general, a las más acaudaladas familias tetuaníes y españolas. La inmensa mayoría de los chalets que se edificaron durante estos años, concebidos por sus propietarios como segunda residencia estrictamente veraniega, fueron proyectados por algunos de los más prestigiosos arquitectos españoles que trabajaban en Tetuán (Bravo Nieto, 2000), realzando de este modo el prestigio turístico de la zona ${ }^{3}$.

La población rural del interior de la provincia de Tetuán, que no solía visitar la playa de Río Martín de forma asidua, debido a sus escasas rentas y a la carencia de medios de locomoción, hacía una excepción durante la fiesta del agua, a comienzos del mes de julio, momento en que se festejaba el fin de las cosechas agrícolas. Pero tanto en ese momento como durante el resto de la temporada la población autóctona y el resto de los españoles ocupaban unas porciones precisas de la playa, de tal forma que los distintos colectivos étnicos y sociales nunca llegaban a mezclarse. Aunque no existieran barreras físicas que marcaran esa compartimentación, cada grupo sabía perfectamente el lugar que le correspondía. Lo mismo sucedía con las denominadas «cantinas escolares» promovidas por las autoridades del Protectorado, en las que los niños españoles, musulmanes y hebreos hacían vida al aire libre en pequeños campamentos situados junto a la playa durante pequeñas temporadas semanales o quincenales.

3 Desafortunadamente muchas de las edificaciones de este período histórico han desaparecido en los últimos años como consecuencia del avance del nuevo proceso urbanizador en el que se halla inmerso esta ciudad, que ha acabado arrasando este singular patrimonio arquitectónico, cuya conservación debería haber merecido un mayor esfuerzo por parte de las autoridades locales. 
Al margen de esta pequeña localidad, el resto de la franja litoral controlada por España apenas fue objeto de uso turístico, entre otras razones porque la proporción de población española y europea que residía en las ciudades costeras o en sus inmediaciones era mucho menor que en Tetuán, y la población nativa aun no había descubierto los saludables beneficios del baño en agua de mar. En algunos casos puntuales, como ocurría, por ejemplo, en la pequeña localidad de Rincón de Medik, próxima a Tetuán, la playa estaba inutilizada para el uso recreativo por hallarse emplazada en ella diferentes unidades militares de las que operaban en Marruecos.

Muy poco más pudo hacerse en estos años en aras a la promoción turística, porque la persistente inestabilidad política lo impidió. La única acción digna de reseñar fue la creación en 1919 de la «Junta superior de monumentos históricos y artísticos» del Protectorado (Valderrama Martínez, 1956; Bellido Gant, 2002), dentro de la cual venía funcionando, al menos desde finales de 1927, una Comisión de turismo. A esa Comisión se debía, aparte de otras cosas, la publicación de un libro de Emilio Tubau y Mariano Bertuchi (1927), que a juicio del profesor Martín Corrales «marcó la pauta de la presentación al exterior de Marruecos que se impondría en las tres décadas siguientes por encima de los cambios políticos operados en la metrópolis en el citado periodo» (Martín Corrales, 2013, 242).

\section{EL FIN DE LA GUERRA DEL RIF Y LA REACTIVACIÓN TURÍSTICA DEL PROTECTORADO}

La plena pacificación del Protectorado que se produjo tras la finalización de la guerra del Rif y el cese de las operaciones militares a finales de 1927, abrió nuevas perspectivas de desarrollo en un territorio sumamente castigado por la tremenda violencia del conflicto armado, y completamente desasistido por la Administración española en todo lo referente a inversión de fondos públicos imprescindibles para alcanzar un cierto grado de adelanto material. La elevada concentración en gastos militares que caracterizó a los presupuestos del Protectorado desde 1912, impidió que se destinaran una parte de las asignaciones económicas procedentes del Estado español a inversiones en infraestructuras o en otro tipo de actuaciones territoriales con una finalidad estrictamente civil, las cuales resultaban completamente necesarias para conseguir las mejoras a las que se había comprometido España en el momento de asumir todas aquellas funciones implícitas en la figura jurídica del Protectorado.

En el nuevo escenario político que comenzó a perfilarse en un territorio que se había alejado definitivamente de la conflictividad bélica, resultaba mucho más fácil consagrar pequeñas partidas de los presupuestos a determinados gastos a los que hasta entonces apenas se había prestado atención. Entre ellos la promoción turística de una zona que albergaba numerosos valores materiales e inmateriales dignos de ser dados a conocer a la creciente corriente de visitantes que en la segunda y tercera década del pasado siglo XX habían empezado a desplazarse por España y Europa. Esos desplazamientos turísticos debían contemplarse como una fuente de riqueza, desde luego, pero a nuestro país le interesaba particularmente la presencia de ese flujo constante de turistas para exhibir los resultados «de la bienhechora actividad de la potencia colonizadora» (Martin Corrales, 2007, 84). Como se afirmaba con rotundidad en 1929, más allá de su trascendencia 
económica, el turismo podía considerarse como un excelente propagador de las buenas relaciones espirituales y sentimentales y, desde luego, «el mejor heraldo que pregone el alto grado a que ya hemos llevado la empresa de organización y de paz en Marruecos» (Anónimo, 1929 a).

Pero para poder dar a conocer y difundir el Protectorado entre los potenciales visitantes, era preciso, antes que cualquier otra acción, comprobar de primera mano el estado real que presentaban las vías de comunicación. En los primeros mapas de la zona había quedado patente la enorme extensión que alcanzaban las pistas apisonadas y aquellas otras que sólo eran transitables en verano, frente a las denominadas carreteras de primera, asfaltadas y plenamente utilizables durante todo el año con independencia de las inclemencias meteorológicas ${ }^{4}$. Como esa información cartográfica no era suficiente, a mediados de 1930 la representación en Marruecos del Patronato Nacional de Turismo abordó un estudio exhaustivo de toda la red viaria, que dividió en 55 itinerarios, describiendo las características más importantes de cada trazado y precisando kilómetro a kilómetro el estado del firme ${ }^{5}$. De esta forma se tuvo un conocimiento exacto de la red viaria y, en definitiva, de las posibilidades de movilidad que ofrecía el territorio a los visitantes, una cuestión crucial desde la perspectiva turística.

Lo que dejaba meridianamente claro el estudio del Patronato era la urgencia con la que debían abordarse las mejoras en la mayor parte de la red viaria; unas mejoras que se habían previsto muchos años antes pero que no se habían podido acometer por la consabida falta de consignaciones presupuestarias. A este respecto, dentro de la red básica de carreteras del Protectorado, la que resultaba de ejecución más urgente era la que conectaba Melilla con Tetuán a través de la intrincada montaña rifeña, sin duda la de mayor interés estratégico, pero también la más costosa por las enormes dificultades topográficas que se presentaban a lo largo de su recorrido (Ibn Azzuz, 1952). Desechada la opción de un trazado litoral similar al de la actual «rocade méditerranéenne» (figura 1), y asegurada la financiación de las obras, pudo darse por finalizada la construcción de tan importante infraestructura a finales de 1933, momento en que la carretera fue inaugurada por Alcalá Zamora, presidente de la Republica en aquellos momentos (Sánchez, Rivas y Ricol, 1999). Aparte de reforzar el carácter de capitalidad de Tetuán, al convertir a esta ciudad en el principal punto de partida y llegada de los viajeros que se desplazaban por el Protectorado, la nueva vía de comunicación venia a romper, en parte, el secular aislamiento de la montaña rifeña, «el país ignorado», como lo calificaba la propaganda turística de la época ${ }^{6}$.

4 Croquis general de las carreteras y pistas de Yebala aptas para el turismo automovilista. África. Revista de tropas coloniales. $\mathrm{N}^{\circ}$ 53. 1 de mayo de 1929. Págs. 120-127.

5 Patronato Nacional de Turismo. Representación en Marruecos. Estudio sobre las comunicaciones terrestres. Datos de junio-julio de 1930. Biblioteca Nacional de España. GM/305.

6 Véase Comité Oficial de Turismo: Ketama y el Rif. S.f. (previsiblemente publicado entre mediados de 1933 y 1935). 


\section{Figura 1 \\ ROCADE MÉDITERRANÉENNE. NORTE DE MARRUECOS}

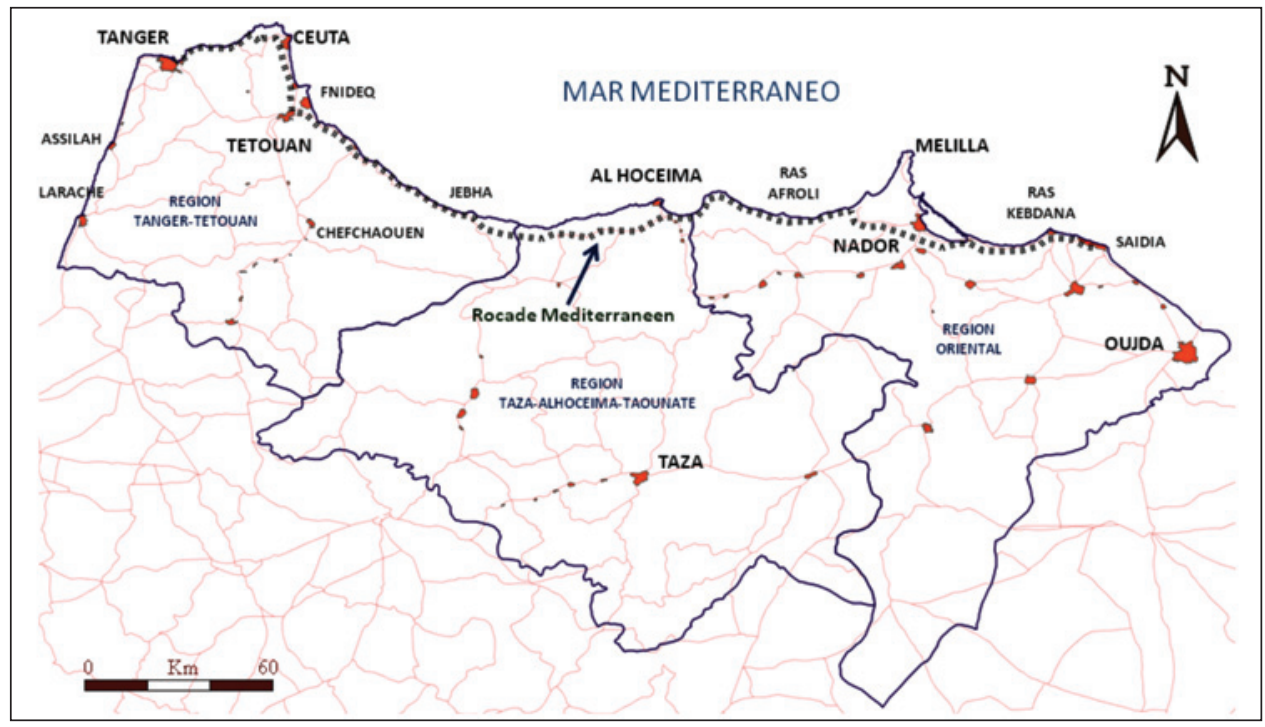

Fuente: Elaboración propia.

Conviene dejar constancia en este momento, por su gran valor testimonial, de un hecho que confirmaba los favorables presagios sobre la importancia turística de esta carretera que se habían expuesto repetidamente. Nos referimos a la apertura, a primeros de noviembre de 1932, del hotel refugio de Ketama (figura 2), situado al pie de la carretera a su paso por el incomparable paraje de Llano Amarillo: un cedral cercano a ese pequeño núcleo urbano que años después se convertiría en punto de cita obligado para muchos españoles. Construido por la Compañía Española de Colonización al tiempo que efectuaba las obras de uno de los tramos de esa carretera, este parador no podía considerarse uno más de los muchos que se habían construido para auxilio de los automovilistas. Según las crónicas periodísticas, era mucho más espacioso y estaba mejor dotado que aquellos, pues sus instalaciones estaban preparadas para la pernoctación y contaban con un mínimo servicio de restauración que se ofrecía a precios módicos. En todo caso, lo más importante del contenido de la reseña de prensa era su llamada de atención acerca del gran proyecto de desarrollo turístico que la empresa colonizadora española tenía preparado para estas tierras rifeñas, consistente en la creación de una pequeña ciudad jardín con chalets individuales y de un gran hotel.

Aunque no tan bien dotadas como la anterior, igualmente fueron objeto de mejoras sustanciales durante estos años el resto de carreteras que desde Tetuán se dirigían a la porción occidental del Protectorado.. El firme de macadam se sustituyó en la mayor parte de ellas por una capa asfáltica que las hacía mucho más rápidas y seguras, sobre todo durante las épocas de lluvias. Así ocurrió con la carretera que conectaba las grandes aglomeraciones urbanas de Tetuán y Tánger, y en la que unía esta ciudad internacional con las poblaciones más occidentales del Protectorado: Arcila, Larache y Alcazarquivir; también con la 


\section{Figura 2 \\ HOTEL REFUGIO DE KETAMA}

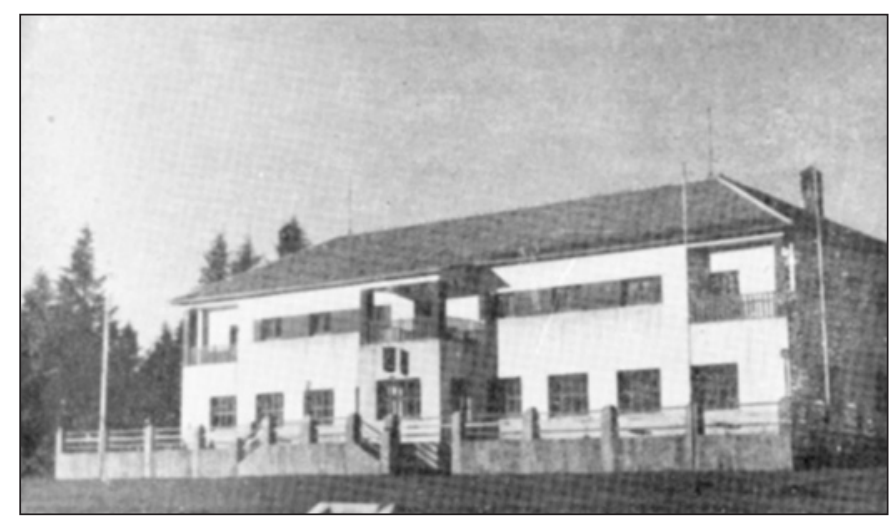

Fuente: Onieva (1947).

carretera que desde Melilla y Nador se dirigía al extremo oriental de la zona controlada por España, cuya frontera estaba situada en el puente sobre el río Moulouya.

A esta mejora le sucedió otra no menos trascendental desde el punto de vista turístico como fue el establecimiento de múltiples líneas de autocares entre las principales ciudades de la zona, todas las cuales eran atendidas por diferentes empresas de capital español. Por medio de estos vehículos, que con los años fueron mejorando en prestaciones y confortabilidad, podían desplazarse por los lugares elegidos todos aquellos turistas que no formaban parte de viajes organizados, para lo cual contaban con una amplia oferta de itinerarios que cubrían en periodos de tiempo cada vez más cortos.

En lo tocante al ferrocarril, junto a la ya citada línea entre Tetuán y Río Martín, existía otra, que entró en servicio a comienzos de 1918, mediante la cual se comunicaba la capital del Protectorado con el puerto de Ceuta (Vidal Pérez y Alberich González, 2004). Paralela a la línea de costa, disponía de estaciones en los pequeños núcleos urbanos y acuartelamientos militares que se hallaban esparcidos a lo largo del recorrido. La conexión ferroviaria entre las ciudades occidentales se efectuaba a partir de la estación ferroviaria situada junto al puerto de Tánger, de donde partía la línea que llegaba hasta Fez. Abierta al tráfico a mediados de 1927, sus estaciones más importantes se hallaban en las proximidades de Arcila y en Alcazarquivir, desde donde partía otra línea con destino a Larache. En la porción oriental, distintas líneas ferroviarias que se habían establecido a principios del siglo XX para la extracción de mineral (Sánchez, Rivas y Ricol, 2001), fueron consagrándose paulatinamente al tráfico de pasajeros. Las más importantes de ellas eran las que ponían en comunicación Melilla y Nador con Segangan y San Juan de las Minas, propiedad de la Compañía Española de Minas del Rif, y la que se adentraba hasta la localidad de Tiztutin pasando por Zeluan y Monte Arruit.

También mejoraron ostensiblemente las comunicaciones marítimas entre la Península y los puertos de Ceuta y Melilla. A comienzos de los años treinta, el primero de ellos estaba regularmente conectado con Algeciras (dos viajes diarios) y con Málaga (un viaje 
semanal). El puerto de Melilla, por su parte, estaba comunicado diariamente con Málaga por un vapor correo, y con Ceuta (un viaje semanal) y Villa Sanjurjo (tres viajes semanales). Otros puertos como el de Larache recibían un vapor correo procedente de Cádiz durante 5 días cada mes.

Estos avances en los sistemas de comunicaciones se vieron secundados por un notable incremento del número de hoteles y de plazas hoteleras así como por una mejora sustancial en la calidad de las prestaciones ofrecidas por los distintos tipos de establecimientos, atentos siempre a las cada vez más refinadas exigencias de los clientes. La apertura, a mediados de 1918, del fastuoso hotel Alfonso XIII, simultáneamente a la de la línea de ferrocarril entre Ceuta-Tetuán, propiedad de la misma empresa que había ejecutado ese trazado, la Compañía Española de Colonización, marcó un antes y un después no ya sólo en la historia turística de Tetuán sino en la de todo el Protectorado. Desde entonces el emplazamiento y la calidad de los servicios turísticos tuvieron un claro referente en ese establecimiento, que la propaganda presentaba como un gran hotel de habitaciones espaciosas y baño con agua corriente, fría y caliente, incorporado a las mismas, que además disponía de servicios propios de intérprete y automóviles a la estación de ferrocarril para el traslado de clientes. Todas estas comodidades resultaban muy avanzadas para los establecimientos turísticos de la época, cuyas prestaciones eran muy inferiores y, por regla general, dejaban mucho que desear.

En una serie de estudios exhaustivos sobre la oferta turística de las principales ciudades del Marruecos español, elaborado en 1931 por la representación en Marruecos de Delegación del Patronato Nacional de Turismo ${ }^{7}$, se incluían, entre otros muchos datos e informaciones, los establecimientos hoteleros que se consideraban apropiados para la recepción de turistas, desechando todos aquellos que a juicio de los redactores de estos informes no reunían las condiciones de habitabilidad necesarias para ser calificados como alojamientos turísticos. En el Cuadro 1 presentamos agrupada esa información sin distinguir el tipo ni la categoría del establecimiento, simplemente para que quede constancia de la oferta existente en ese momento crucial de la historia española.

\section{Cuadro 1 \\ ESTABLECIMIENTOS TURÍSTICOS. 1931}

\begin{tabular}{|l|c|c|c|}
\hline Ciudad & $\mathrm{N}^{\circ}$ establecimientos & Habitaciones & Plazas \\
\hline Alcazarquivir & - & - & - \\
\hline Arcila & 2 & 18 & 22 \\
\hline Larache & 2 & 78 & 93 \\
\hline Tetuán & 7 & 197 & 265 \\
\hline Villa Sanjurjo & 1 & 50 & 70 \\
\hline Xauen & 1 & 5 & 10 \\
\hline Total & 13 & 348 & 460 \\
\hline
\end{tabular}

Fuente: Patronato Nacional de Turismo. Citado en nota.

7 Los trabajos mecanografiados correspondientes a las distintas ciudades están depositados en la Biblioteca Nacional de España. AFRGFC 385/10 (Xauen y Villa Sanjurjo); 385/11 (Arcila); 385/12 (Larache); 385/13 (Tetuán) y 385/20 (Arcila, Alcazarquivir, Larache y Ceuta). 
Como era lógico, entre todas las ciudades del Protectorado descollaba Tetuán, donde se contabilizaban más de la mitad de los establecimientos (todos ellos hoteles excepto una pensión) y casi el $60 \%$ de todas las plazas; un volumen de oferta apropiado para dar respuesta a los visitantes que en aquellos años utilizaban esta clase de alojamientos de máximo confort. Aunque el estudio del Patronato sólo recogía una pensión en Tetuán, lo cierto es que en la capital del Protectorado existían muchos más establecimientos de esta categoría, si bien es verdad que sus múltiples deficiencias funcionales no los hacían aconsejables para el acogimiento de turistas, por lo que el Patronato no consideraba apropiado incluirlos en su listado. Se trataba de alojamientos de ínfima calidad, utilizados mayoritariamente por la soldadesca española en días de permiso, o por los habitantes del medio rural que acudían a la capital del Protectorado para realizar toda clase de gestiones o recibir atenciones de distintos profesionales tetuaníes. Ocasionalmente también eran frecuentados por familiares de los soldados españoles estacionados en la ciudad cuando acudían a visitarlos desde España.

Todos los hoteles se hallaban localizados en el moderno y flamante ensanche de la ciudad, que había empezado a ejecutarse inmediatamente después de formalizarse la constitución del Protectorado (Lobillo Aranda y Ruiz Cupido, 2008). Algunos de ellos, como el mencionado Hotel Alfonso XIII, pertenecían a empresas que trataban de introducirse en el sector, mientras que otros eran propiedad de empresarios con una dilatada experiencia turística que habían decidido modernizar y ampliar sus viejas pensiones, radicadas en su mayor parte en la calle Luneta, estableciendo sus nuevos negocios en la que pasaba por ser la parte más moderna («europea», se decía en los textos de la época en clara señal de distinción) de la ciudad.

La rentabilidad de las empresas hoteleras estaba garantizada, sobre todo, por los numerosos actos sociales que continuamente se celebraban en sus salones y restaurantes, promovidos tanto por las autoridades civiles de la Alta Comisaria como por los jefes de las diferentes unidades del ejército. La prensa diaria daba cuenta sistemáticamente de este tipo de eventos sociales que a ojos de la opinión pública prestigiaban a sus organizadores. Tetuán era en aquellos años que sucedieron a la guerra del Rif una ciudad en plena ebullición demográfica y socioeconómica en la que nunca faltaban motivos para conmemorar algún acontecimiento personal o efeméride histórica de gran calado social.

El resto de los establecimientos distribuidos por las distintas ciudades del norte de Marruecos, independientemente de su categoría, se habían creado con la finalidad de dar respuesta al continuo movimiento de tropas y funcionarios destinados en el Protectorado. A esas ciudades solían llegar a diario numerosos transeúntes procedentes de España cuya misión no era otra que encargarse de la administración civil o la defensa militar de la zona, todos los cuales no tenían más remedio que recurrir temporalmente a hoteles, fondas y pensiones para su hospedaje, en tanto encontraban un alojamiento permanente en el que poder instalarse después con la familia que había quedado en nuestro país. En menor medida que en Tetuán, los salones y comedores de estos establecimientos también se utilizaban para actos oficiales de protocolo y celebraciones privadas que solían organizarse con motivo de ascensos o traslados tanto de funcionarios civiles como de personal militar. Todos estos actos contribuían decisivamente a la rentabilidad de muchos de estos pequeños negocios familiares. 
La única excepción a lo apuntado la constituía el parador de Xauen, promovido por iniciativa del Comité Oficial de Turismo del Protectorado, al que ahora nos referiremos, y financiado por la Junta de Servicios municipales de la ciudad yebalí. Era la forma más apropiada de imitar el proceso de constitución de algunos paradores nacionales de turismo que coetáneamente habían empezado a construirse en algunas ciudades españolas y que, como Xauen, tenían un relevante significado histórico y un indiscutible atractivo artístico y cultural. La construcción del parador se inició a finales de los años veinte, en paralelo a la de otros edificios públicos e infraestructuras urbanas que formaban parte del plan de ensanche de la ciudad (Bravo Nieto, 2000). Sus obras concluyeron a comienzos de 1930, momento en que decidió ponerse a la venta el edificio, o bien arrendarse para su explotación por la iniciativa privada. Además del atractivo de la edificación y de sus modernas instalaciones, el parador ocupaba un lugar estratégico del casco urbano, ya que se hallaba contiguo a la Medina y perfectamente comunicado con la misma a través de la puerta abierta en el lienzo de la muralla que envolvía la ciudad. Por ello se esperaba que el parador fuese una pieza codiciada por los empresarios que empezaban a vislumbrar en el fuerte atractivo de Xauen un suculento nicho de negocio turístico. Inicialmente disponía de 5 habitaciones dobles y un restaurante anexo, aunque poco después de inaugurarse se abordaron las obras para dotarlo de otras 10 habitaciones y mejorar algunas de sus prestaciones.

\section{EL COMITÉ OFICIAL DE TURISMO}

La ejecución de una infraestructura básica de comunicaciones terrestres y marítimas, así como la apertura de numerosos establecimientos hoteleros, eran imprescindibles pero no resultaban suficientes para el afianzamiento del turismo en el Protectorado. Se necesitaba también apoyo institucional para dar a conocer todos aquellos valores naturales y culturales que fueran susceptibles de generar una mínima corriente turística hacia esa porción del territorio norteafricano.

Con esta finalidad, a comienzos de 1927 el turismo quedó integrado funcionalmente en la sección quinta de la Dirección de colonización que se creó en ese momento. Inicialmente los asuntos turísticos los asumió una «Comisión especial de turismo», aunque no siempre, ni siquiera en la documentación o en las publicaciones oficiales, se aludiera a ella con ese nombre (Anónimo, 1929 b). Una de las primeras iniciativas de este organismo consistió en la celebración de un concurso para la redacción de una Guía de visitantes de Marruecos que debía respetar un índice preestablecido. La guía no debía de tener una extensión superior a las 120 páginas, incluidos los mapas, planos, gráficos y grabados. Poco después, con motivo de la organización de los servicios de propaganda y turismo, se creó el Comité oficial de turismo, presidido por el Director de colonización e integrado por 13 vocales en representación de la Administración y de los empresarios del sector. Entre las funciones que se encomendaron al Comité figuraba en un lugar destacado la difusión de «las riquezas, bellezas y curiosidades que de orden natural, artístico, cultural e histórico ofrecen el territorio y la civilización de Marruecos», para lo cual colaboraría con el Patronato Nacional de Turismo que acababa de constituirse en España (Moreno Garrido, 2010). Recordemos que este organismo estatal, a efectos de la organización del turismo, dividió España en regiones, la quinta de las cuales comprendía Andalucía, Canarias y el Protectorado de Marruecos. 
De acuerdo con estos fines el Comité desarrolló desde un primer momento una amplia labor de contenido eminentemente propagandístico, encaminada a dar a conocer los múltiples recursos turísticos, no ya sólo a los visitantes españoles, sino también a la corriente turística europea, especialmente a la de procedencia francesa, que era la que más podía sentirse interesada por estas tierras en su visita a la zona marroquí controlada por Francia. Para ello elaboró numerosos estudios en colaboración con el Patronato Nacional de Turismo, y edito distintos folletos y carteles en diferentes idiomas (figura 3), cuya confección encargó a las figuras más brillantes y reconocidas de la intelectualidad residentes en el Protectorado, entre las cuales sobresalió el citado Mariano Bertuchi (Bouzaid, 2013).

\section{Figura 3 \\ CARTEL DEL COMITÉ OFICIAL DE TURISMO}

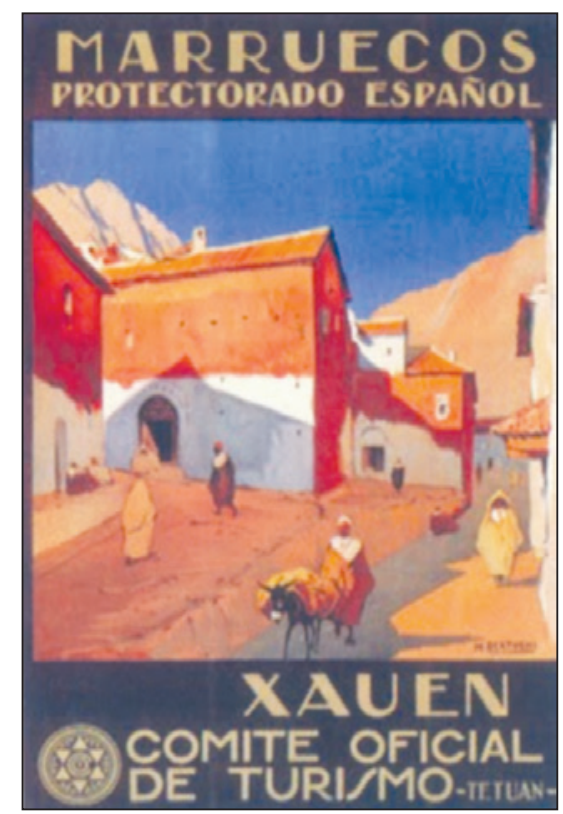

Fuente: reproducción facsímil.

La fuerza expresiva y el incuestionable valor de las imágenes se reforzó aun más en los textos que vieron la luz en los primeros años de funcionamiento del Comité, bien en los folletos divulgativos redactados en varios idiomas para su difusión desde las oficinas turísticas españolas y marroquíes, bien en los numerosos reportajes que la prensa española dedicó al Protectorado tras la pacificación, sufragados en no pocas ocasiones por el propio Comité. En unos y otros no dejaron nunca de enfatizarse los abundantes reclamos que ofrecía el territorio marroquí a un viajero ávido de conocer escenarios que en muchos casos no se alejaban tanto de los ambientes españoles más frecuentados por el turismo (Anónimo, 1929 b, 72). A este respecto las ciudades de Tetuán y Xauen eran con mucha frecuencia el punto obligado de referencia en esas comparaciones. 
Los mapas fueron otro de los instrumentos de difusión turística a los que recurrió el Comité, consciente de la alta utilidad de esta forma de información. El primero de esta naturaleza se editó en 1929 y afectaba al sur de España y Norte de Marruecos, con indicaciones en francés, inglés, alemán y español. A éste le sucedieron otros de escala más precisa que se ceñían a la porción occidental del Protectorado, donde la red principal de carreteras estaba casi completamente terminada, y en la que el control militar del territorio resultaba más intenso, por lo que la seguridad de los itinerarios quedaba asegurada y no había necesidad de adoptar ningún tipo de «precaución excepcional», como aseguraban algunos turistas que habían viajado por ellos (Fernández Ascarza, 1930). Además de representar el estado en que se encontraba el firme de cada tramo de carretera, como ya se ha indicado, la cartografía incluía otros muchos elementos de interés para el turista que transitara por estas vías; desde los talleres de reparación de automóviles y las cantinas, a los lugares de la ruta en los que se podía contemplar un «hermoso paisaje», por citar sólo algunos ejemplos.

Complementariamente a su labor propagandística, el Comité actuó en otros muchos frentes como el ya citado de su participación en la construcción del Parador de Xauen. Consciente de que una de las principales limitaciones para el desarrollo turístico radicaba en el precio de los pasajes marítimos del paso del Estrecho, consiguió que las compañías navieras los rebajaran y que desapareciera el recargo especial para los automóviles que hacían el trayecto Algeciras-Ceuta. Por otro lado, el Comité asumió funciones de vigilancia de los monumentos, museos, parques y demás lugares con atractivo turístico a fin de que se mantuvieran en buen estado de conservación y dispuestos en todo momento para la acogida de visitantes. Igualmente se encargó de la inspección de hoteles, medios de transporte y demás servicios relacionados con el turismo.

Pero posiblemente el acto de mayor resonancia mediática en el que se involucró el Comité en estos años fue en la preparación Exposición Iberoamericana de 1929, que, como es sabido, se celebró en Sevilla entre mediados de 1929 y 1930. En dicho evento, dedicado, como su propio nombre indica, al conjunto de países iberoamericanos con los que Sevilla había mantenido una vinculación secular, se optó por incluir también a Marruecos. Hubiera sido más lógica su inclusión en la Exposición Internacional de Barcelona, que abrió sus puertas ese mismo año, pues en ésta España habría tenido el mejor escaparate «para vender y reivindicar frente a las potencias coloniales europeas, la presencia colonial de España en África» (Sánchez Gómez, 2006, 1049). No obstante, la cercanía geográfica de Sevilla al norte de África, y los contactos de Andalucía con esas tierras allende el Estrecho, no hacían tan descabellada la opción elegida (Fernández, 1929; Darías Príncipe, 1998).

Mediante todas estas acciones no cabe duda que logró popularizarse la imagen del Protectorado y generar un cierto atractivo hacia estas tierras en el que tuvo su origen a una corriente turística incipiente pero de un enorme interés, reconocida incluso por los técnicos de la Administración franquista. A pesar de que la parquedad de las cifras oficiales sobre movimiento turístico fue notoria durante todo el Protectorado, sabemos que en 1929 habían visitado Tetuán un total de 17.000 turistas, y que en el primer semestre de 1930 las visitas habían crecido respecto a ese mismo período del año anterior. Calculando un gasto medio por persona de 17 pesetas diarias, el turismo había dejado en la capital del Protectorado 225.000 pesetas, «cifra ésta que representa una aceptable iniciación de la 
corriente turística ${ }^{8}$. Estamos plenamente convencidos, aun sin disponer por el momento de datos fiables para poder corroborarlo, que esa corriente se acrecentó durante el sexenio republicano. Sin embargo, nada más iniciarse la guerra civil esa tendencia ascendente se quebró dando al traste con todas las expectativas económicas que se habían creado. Y ello no tanto por lo que acaeció en el Protectorado, donde apenas se dejaron oír los ecos de aquella tremenda contienda, como por lo que desde la aciaga fecha del 18 de julio de 1936 se desencadenó en España.

\section{EL SERVICIO DE TURISMO DURANTE EL FRANQUISMO}

Aunque el período que siguió a la guerra civil española resultó especialmente crítico para la economía y la sociedad española, por las carencias de todo tipo que originó el aislamiento exterior de nuestro país, la política de promoción turística del Protectorado no sólo se consolidó sino que se dieron nuevos pasos en pos de su potenciación, ya decididamente vinculada a la capacidad de creación de riqueza de esta actividad y, en definitiva, al desenvolvimiento económico de Marruecos. Ya lo había previsto una década antes Francisco Carcaño en uno de los primeros estudios consagrados expresamente a buscar los medios para fomentar el turismo en las poblaciones del norte de Marruecos (Carcaño Más, 1929). A efectos administrativos, desde el comienzo de los años cuarenta todo lo relacionado con el turismo quedó incluido en un Servicio adscrito a la Delegación de Economía, Industria y Comercio, cuyo cometido principal era la revalorización económica de la zona y la organización y fomento de su actividad comercial. Posteriormente, por efecto de la aplicación del presupuesto de 1945, el Servicio pasó a formar parte de la Delegación de Educación y Cultura, en el que permaneció hasta el momento de la independencia de Marruecos.

El suplemento de crédito de 100.000 pesetas que se aprobó a mediados de 1940 para gastos de cartelería, publicaciones y otro tipo de propaganda, era una señal inequívoca del nuevo empuje que el régimen de Franco, ya plenamente consolidado, pretendía darle al turismo. El cambio de adscripción, además, trajo aparejado un paulatino incremento de la plantilla de personal, al que cada día se exigía una mayor cualificación profesional, y distintos cambios de ubicación de las dependencias del Servicio. En 1947 de manera definitiva quedaron emplazadas en una de las principales arterias del ensanche de Tetuán, sin duda para mostrar el realce que quería darse a la promoción turística de esta ciudad y, por supuesto, del resto del Protectorado. Junto con esa sede central, el Servicio contó con una delegación en Tanger entre 1940 y 1945, cuando la ciudad quedó bajo influencia española, y otra en Larache a partir de 1946.

Entre las múltiples líneas de actuación del Servicio una de las más conocidas fue la organización de circuitos turísticos, los primeros de los cuales partían de Sevilla y durante una semana recorrían los principales centros urbanos de la porción occidental del Protectorado: Tetuán, Xauen, Larache, Arcila y Alcazarquivir, por este mismo orden. Más tarde el radio de acción de esas visitas se alargó y se amplió a dos semanas el tiempo de duración. En este caso los turistas recorrían todo el Protectorado, adentrándose en la montaña

8 Comité Oficial de Turismo. Tetuán. Dirección de Colonización. Información general. Biblioteca Nacional de España. GMC/35/436. 
rifeña a través de la carretera que se había abierto al tráfico a finales de 1933 y visitando Nador y Melilla antes de finalizar el recorrido en el cabo de Tres Forcas. Como curiosidad más destacable de este largo itinerario, los viajeros hacían escala durante tres días en la localidad de Ketama, donde acababa de abrir sus puertas un pequeño establecimiento turístico al que ahora después nos referiremos. Tan larga estancia en pleno corazón del Rif estaba motivada, sin lugar a dudas, por el atractivo que ejercía el monumento situado en Llano Amarillo. En este lugar, según opinión generalizada entre los historiadores, tras unas maniobras militares desarrolladas en los primeros días de julio de 1936, se habían conjurado los jefes del ejército destinados en Marruecos para sublevarse contra la República. Para recordar semejante acto de sedición, se había levantado un gigantesco monolito entre la masa de cedros que envolvían Ketama, el cual había acabado convirtiéndose en uno los lugares de referencia de la mitología franquista.

Tampoco se descuidó en estos primeros momentos de posguerra la labor propagandística del Servicio. El balón de oxigeno que supuso el suplemento de crédito, permitió seguir editando todo tipo de carteles, folletos y planos en grandes tiradas (postales de Erwin Hubert, tríptico de Tetuán, etc.), a los cuales muy pronto se sumaron las primeras guías turísticas del Protectorado, en cuya edición colaboró activamente el Servicio. De entre todas éstas, consideramos particularmente interesante la escrita por Antonio Juan Onieva, un experto en esta clase de publicaciones que a lo largo de casi 600 páginas demostraba con suficiencia haber recorrido el Protectorado paso a paso y visitado sus más llamativos rincones. Tras una extensa parte introductoria en la que desgranaba las principales características físicas y humanas del territorio, describiendo y situando todos aquellos elementos que podían serle de más utilidad al viajero, Onieva efectuaba una explicación pormenorizada de la historia y de los principales atributos turísticos de la totalidad de ciudades de la zona, incluyendo entre ellas Tanger, Ceuta y Melilla, aunque ninguna de las tres tuviera que ver nada con el Protectorado pero sí, y mucho, con el norte de Marruecos (Onieva, 1947).

Por último no queremos dejar de reseñar la participación del Servicio en la organización de la XV Asamblea de la Federación Española de Centros de Iniciativas y Turismo, que tuvo lugar en Tetuán a finales de septiembre de 1950. Aunque no se explicitara, se trataba, sin duda, de una especie de puesta de largo del Protectorado a través de la cual las más altas autoridades españolas de la zona, convencidas de las potencialidades del territorio marroquí, reclamaban un espacio propio y diferenciado dentro de la política turística española, que ya en aquel momento empezaba a desplegarse con todas sus fuerzas.

\section{INFRAESTRUCTURA DE ACOGIDA}

A pesar de que no disponemos de ninguna estadística sobre el particular, estamos firmemente convencidos de que el número de turistas en el Protectorado no debió incrementarse de manera sensible durante la década de los años cuarenta, en buena medida por la penuria generalizada de la sociedad española y por el clima bélico bajo el que vivió Europa durante esos años. Esas circunstancias, lejos de lo que era habitual en otras clases de negocios que solamente emergían en tiempos venturosos, no disuadieron a los empresarios ni a la Administración a la hora de promover nuevas iniciativas relacionadas con el turismo, aun a sabiendas del riesgo que corrían. 
Si damos por validos los datos sobre establecimientos turísticos que aportaba Onieva en su documentada y fiable Guía (Cuadro 2), está claro que el número de éstos había crecido considerablemente entre 1931 y 1947, al pasar de 13 a 50, si bien es verdad que nada se decía acerca de la calidad de los mismos; un aspecto que, como se recordará, había llevado a excluir a muchos de ellos del listado de 1931. Por otro lado, lo que demostraban esos datos es que no sólo las grandes ciudades, sino también otros núcleos más diminutos, disponían de algún establecimiento consagrado expresamente a la acogida de visitantes. Eso significaba que el turismo podía practicarse en muchos más rincones del Protectorado, con lo cual podían difundirse sus beneficiosos efectos económicos y contribuir a propagar la imagen benefactora de la acción española.

Cuadro 2

ALOJAMIENTOS TURÍSTICOS. 1947

\begin{tabular}{|l|c|c|c|}
\cline { 2 - 4 } \multicolumn{1}{l|}{} & Hoteles & Pensiones & Otros \\
\hline Alcazarquivir & 2 & 3 & \\
\hline Arcila & 1 & 2 & \\
\hline Beni Hadifa & & & 1 \\
\hline Ketama & & & 1 \\
\hline Larache & 2 & 6 & \\
\hline Nador & & 2 & \\
\hline Targuist & 1 & 1 & \\
\hline Tetuán & 5 & 14 & \\
\hline Villa Sanjurjo & 5 & 2 & \\
\hline Xauen & 2 & & \\
\hline Total & 18 & 30 & 2 \\
\hline
\end{tabular}

Fuente: Onieva, 1947. Citado en la bibliografía.

Como ya sucediera a comienzos de los años treinta, continuaba sobresaliendo la ciudad de Tetuán como principal enclave turístico del Protectorado, con un total de 19 establecimientos, si bien sólo cinco de ellos estaban clasificados como hoteles. Ya en ese momento había desaparecido el fastuoso Hotel Alfonso XIII, probablemente porque la empresa propietaria, ajena al mundo de la hostelería, no había obtenido todos los beneficios que esperaba. Sus instalaciones las ocupaba ahora el Hotel Nacional, y aunque durante un tiempo había seguido siendo el establecimiento al que recurrían las máximas autoridades españolas y del Protectorado para sus celebraciones oficiales, había perdido buena parte de sus atributos de antaño. Para remediar la carencia de hoteles de la más alta categoría y no agrandar más la brecha existente entre la capital del Protectorado y la ciudad internacional de Tánger en cuanto a calidad de los establecimientos hoteleros, muy profunda ya desde finales de los años veinte (A.C., 1929), el propio Jalifa había tomado cartas en el asunto y decretado, en abril de 1948, la celebración de un concurso para la construcción de un hotel de lujo en el borde meridional de la cornisa de la ciudad, cuya transformación urbanística mediante la erradicación de instalaciones militares 
era una apuesta que también compartía la Alta Comisaria. El hotel, según el pliego de condiciones que se dio a conocer en el Boletín oficial de la zona, debía tener una capacidad aproximada de 60 habitaciones «con posibilidades de ampliación y dotado de cuantos servicios, comodidades y riquezas de materiales constructivos se prescriben para la categoría de lujo».

Uno de los participantes en ese concurso, el arquitecto Casto Fernández Shaw, autor de distintas obras en el Protectorado, hizo pública su propuesta en una revista especializada de la época, en la que explicaba que el hotel Emir, como él lo denominaba, constaba de dos edificios, uno principal y otro auxiliar, que enlazaban entre sí a través una serie de terrazas y jardines que constituían una solución arquitectónica ingeniosa y muy llamativa estéticamente (Fernández Shaw, 1955). Hubiera sido, desde luego, un hito turístico mucho más importante que el que supuso la apertura del Hotel Alfonso XIII, pero finalmente la obra no se llevó a cabo debido a que no logró demolerse el cuartel R'kaina, perdiéndose así para siempre, como ha señalado el profesor Bravo Nieto, «las magníficas posibilidades que el terreno ofrecía para este tipo de usos (Bravo Nieto, 1999, 242).

Independientemente del inconveniente que supuso la negativa a abandonar las instalaciones militares, es muy posible que la idea de construir un gran hotel de lujo en Tetuán se desvaneciera para siempre una vez que pudo comprobarse de manera fehaciente que el recién inaugurado Hotel Dersa, ubicado en una amplia manzana del ensanche muy cercana a la que habían elegido las autoridades del Protectorado para su fracasado proyecto, satisfacía con creces las aspiraciones turísticas de la ciudad en cuanto a calidad y tamaño de las instalaciones hoteleras. Con una capacidad de 100 plazas, constituía el mayor hotel que hasta ese momento se había construido en Tetuán hasta aquel momento. Sus amplios salones y el resto de sus instalaciones estaban pensados para dar respuesta a los turistas que viajaban en grupos organizados así como para atender a todo tipo de celebraciones colectivas de la sociedad tetuaní.

De los restantes hoteles que abrieron sus puertas en este periodo de tránsito entre la II República y el primer franquismo el más original de todos ellos por su ubicación en pleno corazón de la montaña rifeña fue el Parador ubicado en la pequeña comuna rural de Ketama (actual Issaguen). Empezó a construirse en 1938 por iniciativa del empresario español José Llodrá, propietario de la empresa de autobuses «La Valenciana», que cubría el tortuoso trayecto entre Tetuán y Melilla (Llodrá Issaco, 2007). Fue proyectado por el ya mentado José Miguel de la Quadra Salcedo, que había realizado varias obras para esta misma familia en la ciudad de Tetuán. Constaba de 26 habitaciones, comedor y dos salones, además de una pequeña cantina que se encontraba separada del cuerpo principal del edificio, donde se atendía a los conductores y viajeros de esta línea, que en los primeros años de funcionamiento tardaba en recorrerse 17 horas.

El acceso al parador mediante una línea regular de viajeros facilitó muy pronto la llegada a Ketama de turistas procedentes de Tetuán y, sobre todo, de Melilla, los dos núcleos urbanos de mayor entidad demográfica y pujanza económica de toda la zona que se encontraba bajo dominio español. A juicio de quienes lo visitaron, el parador se hallaba muy concurrido durante la estación veraniega. Constituía una alternativa clara al turismo de sol y playa que se practicaba en el litoral, al tiempo que permitía el contacto con el aire puro del Rif, cuyas virtudes terapéuticas siempre fueron muy alabadas. 
A este respecto, en algún momento llegó a sugerirse la idea de instalar en la localidad un sanatorio destinado a tratar a pacientes con enfermedades respiratorias. Durante el invierno, el atractivo fundamental del parador residía en la presencia de nieve en sus inmediaciones durante varios meses. Ese fenómeno natural animaba a muchos habitantes de las zonas litorales a desplazarse hasta Ketama para contemplar y disfrutar de este vistoso espectáculo. Por último, no podemos omitir a los aficionados a la caza mayor y menor que también solían frecuentar el parador para practicar este deporte en sus inmediaciones.

Al margen de esa vertiente lúdico deportiva, el parador se convirtió en un centro muy frecuentado por las autoridades políticas y militares del Protectorado por su proximidad al ya citado Llano Amarillo. En 1954 las instalaciones fueron arrasadas por un incendio, lo que obligó a la familia Llodrá a reconstruirlas, aprovechando la ocasión para reformar por completo el edificio y ampliar su capacidad de acogida.

También experimentó un proceso de ampliación el parador de Xauen, cada día más concurrido por turistas españoles y extranjeros, en viajes individuales o colectivos, que habían hecho de esta «ciudad misteriosa» un punto obligado de estancia en sus visitas al Protectorado. Tras concluir las obras de reforma, el parador volvió a abrir sus puertas al público a mediados de septiembre de 1953. Para entonces había incrementado su capacidad de acogida y experimentado una notable mejora en el resto de sus instalaciones: salones, comedor y especialmente su espectacular terraza con vistas al valle del Lau y a la montaña rifeña.

Un método muy similar al que se había seguido en Xauen, se adoptó a la hora de construir el pequeño hotel municipal de la localidad costera de Arcila, carente de este tipo de establecimientos hasta que la Junta Municipal de la localidad, a mediados de 1943, decidió establecer las bases para la contratación de las obras. La afluencia de turistas a esta pequeña ciudad de la costa atlántica durante los meses veraniegos debía alcanzar en aquel momento una cierta notoriedad por lo que ante la inhibición de la iniciativa privada el Ayuntamiento no tuvo más remedio que actuar como promotor de esta infraestructura de acogida. Dotado de 14 dormitorios y completamente amueblado y equipado, la explotación del hotel se ofreció a la iniciativa privada a finales de 1947. La oferta de arrendamiento se realizaba por un plazo de tres años, prorrogables a voluntad de las partes.

De todas las ciudades del Protectorado, donde más creció la oferta hotelera fue, sin duda, en Villa Sanjurjo, una ciudad de nueva planta que, como se sabe, había empezado a levantarse paulatinamente a partir de 1926. En 1947 contaba con 5 hoteles, los mismos que Tetuán, algunos de ellos con una capacidad que superaba el medio centenar de plazas. Esta amplia oferta hotelera estaba justificada por el enorme trasiego de trabajadores de todas las procedencias y oficios imaginables que resultaban imprescindibles, por un lado, en la construcción de una ciudad que se ampliaba y equipaba a un ritmo vertiginoso, y, por otro, en la ejecución de algunas de las múltiples obras públicas que habían empezado a ejecutarse en las aisladas estribaciones de la montaña rifeña. Decenas de estos trabajadores forasteros llegaban a diario hasta el pequeño puerto de la nueva ciudad, el más activo y de mayor calado de los comprendidos entre Ceuta y Melilla, y se alojaban en esos establecimientos de manera provisional. 


\section{SERVICIOS Y ATRACTIVOS PARA EL TURISMO}

Las sustanciales mejoras en la infraestructura de acogida vinieron acompañadas, en los años que siguieron a la guerra civil española, de otros avances notables en orden al desarrollo del turismo en el Protectorado que no podemos obviar. Entre ellos hay que citar, en primer lugar, el cambio trascendental que se produjo en el sistema de comunicaciones aéreas y marítimas entre España y el norte de África, que si bien nada tuvo que ver con el impulso turístico, acabó favoreciendo sobremanera el tráfico de viajeros entre las dos orillas del Mediterráneo. Los puertos de Ceuta y Melilla, ampliados y completamente reformados, se erigieron desde finales de los años cuarenta en los principales puntos de entrada de personas y mercancías al continente africano, desechándose definitivamente para ese menester los diminutos puertos Villa Sanjurjo y Río Martin, arrasados por el temporal de 1949. Únicamente mantuvo una cierta actividad el puerto atlántico de Larache pero en modo alguno comparable con la de las dos plazas españolas.

Más que la frecuencia de los buques que a diario recalaban en los puertos de Ceuta y Melilla procedentes de Algeciras y Málaga, se incrementó de un modo ostensible su capacidad de carga, al entrar en servicio algunos grandes barcos construidos en los astilleros españoles, que sin demasiadas dificultades permitían el traslado de los vehículos personales de los pasajeros. De este modo el recorrido por Marruecos resultaba mucho más cómodo al no tener que depender de los horarios y las rutas de los transportes públicos. Así mismo se redujo el tiempo de duración de la travesía y el viaje se hizo mucho más placentero, especialmente la conexión entre Algeciras y Ceuta, cuya duración no sobrepasaba las 1,5 horas.

Por su parte el transporte aéreo conoció mejoras de importancia al abrirse plenamente al tráfico de pasajeros el renovado aeródromo de Sania Ramel, próximo a Tetuán; una vieja aspiración del Patronato Nacional de Turismo, que en 1930 había solicitado el establecimiento de una línea aérea de transporte entre Sevilla y Tetuán, destinada exclusivamente al desplazamiento de turistas. Tuvieron que transcurrir siete años hasta que en octubre de 1937 la compañía de aviación española Iberia, al poco de su creación, estableciera una línea regular de viajeros con el Protectorado, aunque no precisamente con los fines que había propuesto el Patronato. Fue la primera línea regular de viajeros de esa empresa y recorría buena parte del territorio que en aquel momento controlaba el ejército rebelde: partía de Vitoria y tras pasar por Salamanca, Cáceres y Sevilla, finalizaba en Tetuán. Poco después, pasados los efectos de la guerra, se establecieron otras líneas regulares con una finalidad eminentemente civil que conectaban a diario Tetuán con Sevilla y Madrid, y en días alternos con Melilla y con Málaga. Otro vuelo semanal entre Madrid y Villa Cisneros hacía escala en Tetuán.

Esa posibilidad de desplazarse rápidamente desde Madrid a la capital del Protectorado, fue la que auspició la creación del paquete turístico «Una semana en Marruecos», promovido directamente por la Alta Comisaria en 1952 y coordinado por quien en aquel momento actuaba como agente de enlace en España para cuestiones turísticas: José Olmo Boullón, autor del libreto en el que se detallaban las características de los lugares a visitar cada jornada y las instrucciones a las que debían atender el colectivo de viajeros (Olmo Boullón, 1952). Como ya había sucedido con otras propuestas anteriores, el viaje se 
limitaba a recorrer la porción occidental del Protectorado, la más cercana al aeródromo, aunque ahora se incluían nuevos atractivos para el visitante. Es interesante detenerse en ellos porque constituyen la mejor muestra de lo que en ese momento podía encontrar el turista en el país norteafricano.

En primer lugar, unas ciudades que ya eran atractivas en sí mismas, no sólo por el tipismo al que se aludía en los años veinte, sino por otras muchas formas de manifestación de la cultura material tanto autóctona como española. En este sentido, al atractivo que siempre habían despertado en el turista español y europeo las mezquitas, medinas y zocos, sobre todo los de Tetuán y Xauen, se unían ahora los espaciosos ensanches como ámbitos urbanos de profundo contraste tipológico y funcional con la ciudad musulmana. En esas prolongaciones podían contemplarse edificaciones de todos los estilos y tamaños, individuales y colectivas, públicas y privadas, obra de los arquitectos nacionales más acreditados y solventes, cuya nómina es extensa en extremo, como puede comprobarse en los trabajos de Malo de Molina y Domínguez (1996) y de Bravo Nieto (2000).

Como reclamos turísticos añadidos, en Tetuán se presentaban distintos espacios expositivos entre los cuales sobresalía el flamante Museo arqueológico, abierto a mediados de 1940, después de que cerrara sus puertas el que venía funcionando desde 1931 (Zomak y Parodi, 2011). Exponía piezas procedentes de las excavaciones que desde comienzos de los años veinte se venían llevando a cabo en los yacimientos de Tamuda y Lixus, situados, respectivamente, en las inmediaciones de Tetuán y Larache, cuyas excavaciones también se ofertaban como uno de los recursos turísticos dignos de ser visitados. El Museo marroquí, de contenido etnológico, creado por Bertuchi en 1928, y la Escuela de Artes Indígenas, a los que se cambió su denominación en 1947 (Bellido Gant, 2010), eran los otros dos centros tetuaníes de visita obligatoria.

Todos estos atractivos podían descubrirse acompañados por «guías interpretes libres autorizados», una figura de apoyo al turismo que se había creado en 1932, posiblemente para evitar la mala imagen que proyectaban la legión de intrusos que sin formación ni cualificación de ningún tipo, se ofrecían a los visitantes para enseñarles Tetuán a cambio de una pequeña remuneración. Para acceder a esa categoría, el Comité y más tarde el Servicio de turismo, exigían unos exámenes rigurosos en los que los aspirante debían demostrar ante un tribunal «conocimientos suficientes del tesoro artístico y bellezas naturales de la zona, a la vez que todos aquellos conocimientos turísticos generales interesantes para el viajero, como son los relativos a comunicaciones, servicios públicos, excursiones, hoteles, restaurantes, tiendas, etc. Aunque inicialmente se había pensado dotar de guías intérpretes a todas las ciudades del Protectorado, lo cierto es que sólo existían en Tetuán, donde en 1949 estaban autorizados media docena de ellos.

Igualmente, en esta ciudad empezaron a constituirse a partir de 1949 una serie de Agencias de viaje que no sólo se encargaban de gestionar los desplazamientos a la Península de los españoles residentes en el Protectorado, sino que organizaban también viajes por el interior del país a quienes lo demandaran. Algunas de estas Agencias, en manos de potentes grupos turísticos que empezaban a organizarse en España, llegarían a alcanzar con los años una gran notoriedad y predicamento entre todos aquellos españoles y europeos despojados de prejuicios que se habían decidido a conocer Marruecos. 
El núcleo playero de Río Martín, por su parte, había incrementado considerablemente su atractivo turístico después de que la Junta de Servicios municipales de la localidad empezara a funcionar con carácter autónomo respecto a la de Tetuán, y apostara decididamente por reforzar el papel residencial de la localidad mediante la exención durante quince años del impuesto urbano a todos aquellos que construyeran una vivienda. Esa decisión disparó la construcción de segundas residencias en el frente costero y a lo largo de la carretera que se dirigía a la vecina Tetuán, a partir del momento en que se aprobó el nuevo plan de urbanización a mediados de los años treinta. Aunque el núcleo urbano seguía sin disponer de una sola plaza hotelera, numerosos establecimientos de hostelería y salas de fiesta se dispersaban a lo largo del frente costero, alcanzando su máximo nivel de concurrencia durante la temporada estival, pero sin dejar de perder la animación el resto del año. Fue durante la dura posguerra española cuando, paradójicamente, Río Martín conoció su época turística de mayor esplendor. Disipadas todas las tensiones y los desgarros personales a los que había dado origen aquel irracional conflicto, las playas y zona urbana de la localidad volvieron a animarse como nunca, hasta que llegó el momento de la independencia de Marruecos en 1956. A partir de ese momento este núcleo pionero quedó relegado a un segundo plano, dado que la Administración turística marroquí en colaboración con las distintas empresas del sector promovieron la implantación de nueva infraestructura en la franja costera situada al oeste de la localidad, comprendida entre Cabo Negro y la plaza española de Ceuta, cuya expansión ha resultado espectacular en los últimos años, hasta convertirse en uno de los destinos mejor dotados y más consolidados de toda la costa que envuelve al Mediterráneo.

\section{BIBLIOGRAFÍA}

A.C. (1929): «Desarrollo de la industria hotelera en Tánger. El Gran Hotel Villa de France», África. Revista de tropas coloniales, $\mathrm{n}^{\circ}$ 53, pp. 136.

ANÓNIMO (1929 a): «El fomento del turismo en la zona de Protectorado español en Marruecos», África. Revista de tropas coloniales, $\mathrm{n}^{\circ}$ 53, pp. 118-119.

ANÓNIMO (1929 b): «Fomento del turismo en la zona española de Protectorado marroquí. África», Revista de tropas coloniales, $\mathrm{n}^{\circ}$ 51, pp. 72.

ARAQUE JIMÉNEZ, E. y GARRIDO ALMONACID, A. (2008): «Koudiat Taifour y la llanura de Tetuán: oportunidades para su conservación», en Taiqui, L., Araque Jiménez, E. y Ýoubi Idrissi, M. (Edit.): Conservación y valorización de Koudiat Taifour. Tetuán, Imprenta Al khalij al arabi, pp. 4-38.

BELLIDO GANT, M.L. (2002): «Promoción turística y configuración de la imagen de Marruecos durante el Protectorado español», Cuadernos de Arte de la Universidad de Granada, no 33, pp. 221-234.

BELLIDO GANT, M.L. (2010): «La promoción de la enseñanza artesanal en Marruecos durante el Protectorado español», en La invención del estilo hispano-magrebí. Presente y futuros del pasado. Barcelona, Antropos, pp. 260-280.

BOUZAID, B. (2013): «Mariano Bertuchi: la enseñanza del arte patrimonial y moderno», en Aragón Reyes, M. (Dir.): El Protectorado español en Marruecos: la historia trascendida. Bilbao, Iberdrola, vol. II, pp. 35-53. 
BRAVO NIETO, A. (1999): «La arquitectura de Carlos Fernández Shaw en Marruecos. Propuestas y realizaciones», en Casto Fernández Shaw, en. Arquitecto sin fronteras. 1896-1978. Madrid, Electa, pp. 233-243.

BRAVO NIETO, A. (2000): Arquitectura y urbanismo español en el norte de Marruecos. Sevilla, Junta de Andalucía.

CARCAÑO MÁS, F. (1929): Labor civilizadora de España en Marruecos. Medios de fomentar el turismo en las poblaciones del norte de África. Melilla, Tip. Luisa Varela.

DARIAS PRÍNCIPE, A. (1998): «La presencia de Marruecos en la Exposición Iberoamericana de Sevilla. Razones de un resurgimiento manipulado», Boletín de Arte, $\mathrm{n}^{\circ}$ 19, pp. 231-244.

FERNÁNDEZ, S. (1929): «Marruecos en la Exposición ibero-americana de Sevilla», África. Revista de tropas coloniales, $\mathrm{n}^{\circ}$ 53, pp. 111-115.

FERNÁNDEZ ASCARZA, V. (1930): «Una excursión a Marruecos (Notas e informaciones para turistas)», Boletín de la Real Sociedad Geográfica, tomo LXX, octubre, pp. 416-436.

FERNÁNDEZ SHAW, C. (1950): «Proyecto de gran hotel en Tetuán», Cortijos y Rascacielos, $\mathrm{n}^{\circ} 55, \mathrm{pp} .23-26$.

IBN AZZUZ, M. (1952): «Planes de revalorización económica de la zona jalifiana de Marruecos», Cuadernos de Estudios Africanos, $\mathrm{n}^{\circ}$ 18, pp. 39-50.

LOBILLO ARANDA, D. y RUIZ CUPIDO, J. (2008): Tetuán. La huella de la ciudad española en Marruecos. Ceuta, Papel de Aguas.

LLODRÁ ISSACO, L. (2007): Vicisitudes de un viejo tetuaní. Antequera, Innovación y Cualificación, S.L.

MALO DE MOLINA, J. y DOMÍNGUEZ, F. (1996): Tetuán. El Ensanche. Guía de arquitectura. Sevilla, Junta de Andalucía.

MARTÍN CORRALES, E. (2007): «Marruecos y los marroquíes en la propaganda oficial del Protectorado (1912-1956)», Mélanges de la Casa de Velázquez, nº 37-1, pp. 83-107.

MARTÍN CORRALES, E. (2013): «Los inicios del turismo en el Protectorado español de Marruecos (1912-1956)», en De Al Andalus a Tetuán. Actas del homenaje al profesor Mhammad M. Benaboud. Tetuán, Imprenta Al Khalij Al Arabi, pp. 235-257.

MORENO GARRIDO, A. (2010): «El Patronato Nacional de Turismo (1928-1932): balance económico de una política turística», Investigaciones de Historia Económica, $\mathrm{n}^{\circ} 18$, pp. 103-132.

OLMO BOULlÓN, J. (1952): Una semana en Marruecos. Tetuán, Servicio de turismo de la Alta Comisaria de España en Marruecos.

ONIEVA, A. . (1947): Guía turística de Marruecos. Plazas de soberanía. Protectorado español. Tanger. Madrid, Artes gráficas Arges.

SÁNCHEZ, A., RIVAS, M. y RICOL, A. (1999): «La red viaria en el Marruecos español (1912-1956): la construcción de la carretera Tetuán-Melilla», Ingeniería Civil, nº 114, pp. 57-64.

SÁNCHEZ, A., RIVAS, M. y RICOL, A. (2001): «Compañías y ferrocarriles mineros en el Marruecos español (1906-1956)», Revisa de Obras Públicas, n 3409, pp. 45-51. 
SÁNCHEZ GÓMEZ, L. A. (2006): «África en Sevilla: la exhibición colonial de la exposición iberoamericana de 1929», Hispania. Revista española de historia, ${ }^{\circ}$ 224, pp. 1045-1082.

TUBAU, E. y BERTUCHI, M. (1927): Tetuán. Unas horas en el barrio moro. Tetuán, Junta superior de monumentos.

VALDERRAMA MARTÍNEZ, F. (1956): Historia de la acción cultural de España en Marruecos (1912-1956). Tetuán, Alta Comisaria.

VIDAL PÉREZ, J. M. y ALBERICH GONZÁLEZ, J. (2004): Los ferrocarriles en los protectorados y colonias españolas en África. Marruecos, Guinea Ecuatorial e Ifni. El cruce de Gibraltar. Rubí, Grafiques 92, S.A.

ZOMAK, M. y PARODI, M. J. (2011): «Apuntes históricos sobre el Museo de Tetuán», Almoraima, $\mathrm{n}^{\circ} 42$, pp. 47-72. 
